\title{
The concordance between EFL learners' stress coping strategies, willingness to communicate, and metacognitive self-regulation
}

Atrian, Anahita

Imam Reza International University, Mashhad, Iran (anahita.atrian@yahoo.com)

Ghanizadeh, Afsaneh $\bowtie$

Imam Reza International University, Mashhad, Iran (a.ghanizadeh@imamreza.ac.ir)

Rostami, Soroor

Imam Reza International University, Mashhad, Iran (rostami.soroor@yahoo.com)

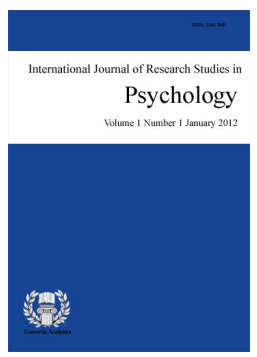

ISSN: $2243-7681$ Online ISSN: 2243-769X

OPEN ACCESS

\section{Abstract}

Granted the fact that willingness to communicate (WTC) in the second or foreign language is the construct that explains the differences in learners' intention to communicate in the L2, it has recently attracted the attention of L2 educationalists. The main purpose of the present study is to delve into willingness to communicate in relation with self-regulation and coping strategies. This study was conducted with 130 undergraduate EFL university students enrolled in the English Language Teaching (ELT) Department of two universities in Iran. The data collection instruments consisted of the translated versions of WTC Questionnaire, the Self-Regulation Trait (SRT) Scale and Coping Inventory for Stressful Situations (CISS). The CISS focuses on three major dimensions of coping in response to a stressful situation: Task-oriented, Emotion-oriented, and Avoidance-oriented coping. Task-oriented coping refers to responses directed at either problem resolution or cognitively reframing the meaning of the stressful situation. Emotion-oriented coping refers to responses directed toward oneself rather than the problem at hand. An individual using this coping style may respond to a difficult situation by becoming emotionally distressed or engaging in fantasy activities. Avoidance-oriented coping refers to responses designed to avoid dealing with the stressful situation, such as distracting oneself with other situations (e.g., shopping) or through interacting with other persons. The data were analyzed descriptively using the SPSS 21 Software. The findings of the study revealed that among the subscales of coping strategies, task strategy had the highest correlation with WTC and self-regulation. Among the subscales of WTC, WTC in speaking displayed the highest correlation with task coping strategy. In addition, there was a moderate correlation between WTC and self-regulation. The correlation coefficients between WTC and the components of self-regulation showed that WTC has the highest correlation with the motivation component of self-regulation. The limitations of the study and implications for future research are addressed.

Keywords: coping strategies; self-regulation; willingness to communicate; EFL learners 


\section{The concordance between EFL learners' stress coping strategies, willingness to communicate, and metacognitive self-regulation}

\section{Introduction}

One of the primary objectives of EFL learning is the utilization of the target language. Moreover, researchers have substantiated the crucial importance of speaking in order to learn in the field of Second Language Acquisition (MacIntyre, Baker, Clement, \& Donovan, 2003). However, it seems that in many English language teaching classes, some students are less eager to involve in the process of communication. Due to the importance of the concept of willingness to communicate (WTC), many studies have extensively been conducted in recent years. The notion of WTC was initially proposed by McCroskey and Baer (1985) with the ultimate goal of clarifying individual differences in L1 communication behaviors, by inverting the negative orientation into a positive orientation. The term WTC was initially introduced with reference to first language (L1) communication, and it was thought to be personality-based, trait-like predisposition that remained stable across different communication circumstances (McCroskey \& Richmond, 1991). WTC in the Second Language is characterized as "a readiness to enter into discourse at a particular time with a specific person or persons, using an L2" (MacIntyre, Clément, Dörnyei, \& Noels, 1998, p. 547). There are many people who avoid entering L2 communication circumstances despite the fact that they have high proficiency. This implies that there is another variable that intervenes between the competence to communicate and putting this competence into practice (Dörnyei, 2005). Although the concept of WTC has been investigated in relation to many individual difference factors, including learning strategy, motivation, working memory, aptitude, and personality, no empirical study to date has examined a stress-associated construct such as coping strategy and a metacognitive factor such ad self-regulation in relation to WTC within a single framework.

The subject of coping with stress has attracted the attention of many researchers in the modern language pedagogy. Likewise, many articles and books have attached great importance to the subject. Consideration has been centered on coping strategies and the ways in which they can ease stress levels and promote higher personal satisfaction. While in the past coping was seen essentially as responsive- a procedure to be utilized once stress had been experienced- recently it is seen as something one can do prior to stress advent (Greenglass, 2002). In addition, coping is the behavioral and cognitive efforts used by individuals in the face of stressful situation, event and demand. According to Lazarus and Folkman (1984), coping strategies can be seen as what an individual really thinks and does in a specific circumstance. They assumed coping strategies to have two essential capacities, managing the problem and governing the emotions relating to the stressors. Appraisal of a situation depends with the coping resources available when one encounters a stressful situation. According to Wilson, Wallston, and King (1990), understanding the nature and effects of stress is linked to the concept of coping, and the availability and use of specific coping mechanisms strongly influences individuals' psychological and physiological responses to stressors. An example of emotional coping strategy is praying to God and trying to seek answers when facing academic stress. Both cognitive and behavioral coping strategies can be effective in modifying the effects that stress can have on individuals.

Problem focused coping and emotion have been propounded by Lazarus and Folkman (1984) in their cognitive transactional model. Mattllin (1990) stated that emotion oriented strategy, efforts are directed at altering emotions and they incorporate endeavors to reframe the problem in a manner that it no more brings out a negative emotional response and inspires less stress. According to Lazarus (1991), emotional focused coping strategies incorporate looking for social support for emotional reasons, and growth, turning to religion, positive reinterpretation acceptance, focus and venting of emotions whilst problem focused coping strategies include active coping, planning, seeking social support for instrumental reasons, restrain, suppression of competing activities and reframing. In a study of the first year students, those with greater positive affect were more likely 
Concordance between stress coping strategies, willingness to communicate, and metacognitive self-regulation

to use, emotion focused coping strategies such as instrumental support to cope with academic stress (Pritchard \& McIntosh, 2003). Those who used emotion-focused strategies because of academic stress were more likely to experience thoughts of dropping out of college, and the individuals who utilized venting were more likely to encounter negative dispositions toward school (Pritchard \& McIntosh, 2003).

Lazarus and Folkman (1984) indicated another type of coping strategy known as avoidant coping strategies; these incorporate alcohol and drug abuse, and behavioral and mental disengagement. Lazarus and Folkman (1984) stipulated that avoidance oriented include coping strategies such as avoiding the situation, denying its existence or losing hope. People who perceive stressful situations as uncontrollable elicit more avoidance strategies. Avoidant coping strategies can be regarded as maladaptive coping strategies as they cause health problems such as impairment of memory, chronic heart diseases and asthma.

Another factor investigated in the present study is self-regulation learning (SRL), also known as academic self-regulation which has initiated lines of research since the late 1970s and 1980s. According to Zimmerman (1990), SRL concerns learners who are set goals for their academic endeavors and tend to control and manage their own learning process. Many definitions have been developed to describe SRL. The common conceptualization of SRL is that learners are self-regulated if they are "meta-cognitively, motivationally, and behaviorally active participants in their own learning" (Zimmerman, 1990, p. 4). Recent definitions of SRL also share the feature of depicting it in terms of cyclical processes or a feedback loop in which learners set goals, self-control and monitor their learning effectiveness, react to this feedback on learning effectiveness, and reset goals or revise learning strategies in subsequent effort (Zeidner et al., 2000; Zimmerman, 1990, as cited in Varasteh, Ghanizadeh, \& Akbari, 2016). Detailed definitions differ depending upon the theoretical perspectives from which they are derived. According to Social Cognitive Theory, SRL is defined in terms of the self-directive processes by which "learners control their thoughts, feelings, and actions" in order to attain goals (Zimmerman \& Schunk, 2001, p. vii).

Social cognitive definitions of SRL share the following four characteristics. First is the pivotal role of personal abilities or attributes for attaining personal goals in SRL. To support this view, it has been found that SRL makes a distinctive contribution to academic achievement in addition to students' general abilities (Schunk \& Zimmerman, 1997; Zimmerman \& Bandura, 1994; Zimmerman \& Martinez-Pons, 1986, 1988). Second is that these personal attributes are not a matter of absence or presence but a matter of degree. Third is that SRL is not just a solitary type of learning but has some social aspects. Finally, it is believed that SRL is not a general trait; it is situation or domain specific (Boekaerts, 1997; Pintrich, 2004; Schunk, 2001). It consists of temporarily orchestrated processes to perform a task, and SRL strategies may be potent in one domain but not in other areas. For example, a student may be more strategic and effective in solving math problems but may not show the same degree of self-directedness while working on writing. This example is supported by empirical evidence that demonstrates students' motivation and strategies vary for different courses (VanderStoep, Pintrich, \& Fagerlin, 1996; Wolters \& Pintrich, 1998).

The main purpose of this study is to delve into willingness to communicate in relation with self- regulation and coping strategy. Viewed from a broader perspective, it seeks to examine and interpret the hypothesized relationships among willingness to communicate, self- regulation, and coping strategy within a single framework. The following research questions are posed and will be investigated in the present study:

$>\quad$ Is there any significant relationship between EFL learner's coping strategy use and their WTC?

$>\quad$ Is there any significant relationship between EFL learner's self- regulation and their WTC?

$>\quad$ Is there any significant relationship between EFL learner's self-regulation and their coping strategy use?

\section{Review of Literature}

The interrelationship between the concepts of self-regulation and willingness to communicate has been 
theoretically asserted in the literature. According to Schunk and Zimmerman (1998), self-regulated learners are commonly described as active subjects who efficiently manage their learning experiences in various ways, including organizing and rehearsing information to be learned, and holding positive thoughts about their abilities, the value of learning and factors that impress learning process. SRL is also the ability to control and influence one's learning processes positively. All these characteristics can plausibly be considered as determinants of readiness to enter into communication with a pre-planned intention and audience in mind. Besides, empirical studies have consistently maintained this association. Heidari Soureshjani (2013), for instance, explored the interrelationship of English as a Foreign Language (EFL) learners' self-regulation, willingness to communicate (WTC), and their oral presentation performance through correlational analysis. The results revealed that there is a significant relationship between the self-regulation degree of language learners and their oral performance. There was also a strong, positive relationship between the WTC level of learners and their oral presentation performance. In addition, Nosratinia and Deris (2015) investigated the association between Willingness to Communicate (WTC) and Self-Regulation (SR) among Iranian English as a Foreign Language (EFL) learners using Spearman's rank-order correlation. The analysis outcomes suggested a significant direct correlation between SR and WTC, standing for a large effect size and a very small confidence interval.

There are different theoretical views of how stress and self-regulation interact. On the one hand, some suggest that stress may deplete one's future self-regulation capacity in what is called a "limited resource" or "strength" model of self-regulation (Muraven \& Baumeister, 2000). However, there are data that contradict this claim and suggest that depletion may have more limited effects than initially thought (Xu, Liu, Zou, Zhang, You, \& Pei, 2014). A model that is well-accepted in the child development literature is that stress and self-regulation have a curvilinear relationship (like an inverted $\mathrm{U}$ ). In other words, some degree of stress may increase arousal, focus, and goal-orientation in a way that enhances self-regulation, while too much stress may decrease it. Indeed, mild and intermittent stress within a child's abilities to cope might actually support the development of self-regulation skills. However, as the level, intensity, or duration of stressors exceeds a child's coping skills and support, self-regulation is expected to decrease (Murray, Rosanbalm, Christopoulos, \& Hamoudi, 2015).

Winterbach (2007) conducted a study to explore qualitative differences in the self-regulation of stress management between students experiencing high stress levels and those experiencing low stress levels. The results indicated that participants with lower stress were better self-regulators. They were slightly more mindful regarding perceived causes of stress, had more intrinsically motivated goals, had higher self-efficacy beliefs, more often used physical activity and external monitoring in executing their stress goals, judged themselves more positively, and reflected more positively on the self-regulation process. In addition, Trevisani (2014) conducted a correlational study of self-regulated learning, stress, and mindfulness in undergraduate students. Results demonstrated that stress was a statistically significant and negative predictor of mindfulness, mindfulness was a statistically significant and positive predictor of SRL, and perceived stress was a statistically significant negative predictor of SRL. Findings demonstrated that in the presence of mindfulness, stress was not a statistically significant predictor of SRL. Results of the bootstrapping analysis provided evidence indicating that mindfulness partially mediated the relationship between stress and SRL. From the literature, it is thus evident that self-regulation is an important component of stress management, which, however, is not well researched and understood within Iranian EFL university student context.

\section{Methodology}

\subsection{Participants}

A total of 130 undergraduate EFL university students participated in this study, including 66 females and 64 males. Participants were selected from two universities. All participants were studying English as an academic major. The range of the age of the participants was between 18 and 35, and the mean age was 21.87 ( $\mathrm{SD}=2.97$ ). The reason for selecting university students majoring in English was that Iranian non-English major university 
students do not develop a functional English proficiency, they do not have the chance to speak in English classrooms, and the class time is limited to only reading and vocabulary. Therefore, asking them for situations that they speak English in classroom may seem irrelevant.

\subsection{Instruments}

The primary instruments used in this study consisted of three questionnaires:

WTC in L2 Questionnaire - WTC questionnaire $(\alpha=.93)$ was used in order to measure the degree of WTC among students. This questionnaire was adapted from MacIntyre, Baker, Clément and Conrod (2001). The Scale measures L2 WTC in four basic skill areas: listening ( 8 items, $\alpha=.83$ ), speaking ( 5 items, $\alpha=.76$ ), reading (6 items, $\alpha=.81$ ), and writing ( 8 items, $\alpha=.83$ ). It also measures students ${ }^{\text {ee }}$ willingness to engage in L2 communication inside the classroom. This questionnaire includes 27 items and the students are asked to choose and answer based on the Likert scale from 1 to 5 . The scales are: (1=almost never willing, $2=$ sometimes willing, $3=$ willing half of the time, $4=$ usually willing and $5=$ almost always willing). In the present study, the translated version of the scale was utilized. The fit indices of the scale computed via CFA were as follows: the chi-square/df ratio $=(2.8)$, the $\mathrm{RMSEA}=(.069), \mathrm{NFI}=.89$ (forthc.).

Self-Regulation Trait Questionnaire (SRT) - To measure self-regulation, the translated version of the Self-Regulation Trait (SRT) Questionnaire designed by O'Neil and Herl (1998) was applied. It consists of 32 Likert-scale questions ranging from almost never, to sometimes, often, and almost always. The scale seeks to measure metacognition and motivation dimensions. Each dimension comprises two sub-scales. Meta-cognition covers the constructs of planning and self-monitoring, and motivation contains effort and self-efficacy. According to Herl et al (1999), the reliability and validity of the scale have been verified in multiple studies. In the present study, the total reliability of the Persian version of the questionnaire calculated via Cronbach's alpha and it proved to be (.73). The questionnaire was translated and validated by the researchers (forthc.) using a confirmatory factor analysis (CFA). The results of CFA were as follows: the chi-square/df ratio $=(2.3)$, the RMSEA $=(.062)$, and NFI $=.90$.

Coping Inventory for Stressful Situations (CISS) - The translated version of CISS designed by Endler and Parker (1990) was utilized. This is a self-report paper and pencil measure of coping containing 48 items. 16 items assess task-oriented coping and 16 items measure emotion-oriented coping. The avoidance scale (16 items) is divided into two subscales: distraction and social diversion. The CISS focuses on three major dimensions of coping in response to a stressful situation: Task-oriented, Emotion-oriented, and Avoidance-oriented coping. Task-oriented coping refers to responses directed at either problem resolution or cognitively reframing the meaning of the stressful situation. Emotion-oriented coping refers to responses directed toward oneself rather than the problem at hand. An individual using this coping style may respond to a difficult situation by becoming emotionally distressed or engaging in fantasy activities. Avoidance-oriented coping refers to responses designed to avoid dealing with the stressful situation. Such attempts to deal with stress may take the form of either distracting oneself with other situations (e.g., shopping) or through interacting with other persons, forms of Avoidance-oriented coping that the authors conceptualized as a Task-oriented avoidance and Person-oriented avoidance, respectively (Endler \& Parker, 1990, 1999).

\subsection{Procedure}

The current research was conducted in Imam Reza international university of Mashhad and Islamic Azad university of Neyshabour, Iran. After obtaining permission from the university chairs and also instructors of the classes for conducting the research, the qualitative data was collected by the distribution of WTC, SRT, and CISS questionnaires among 131 undergraduate university students whose majors were English language translation and teaching. The subjects were invited to participate in the study on a voluntary basis. The researcher emphasized on the importance of answering the question as honestly as possible by assuring them that their 
Atrian, A., Ghanizadeh, A., \& Rostami, S.

personal information would remain confidential. They were just required to provide demographic information such as gender, age, level of education and total grade on their courses level. The data collection procedure was started in December 2015 and ended in November 2015 winter semester.

\section{Results}

To check the normality of data distribution, the Kolmogorov-Smirnov test was employed. This test is used to check whether the distribution deviates from a comparable normal distribution. Table 1 presents the results of the Kolmogorov-Smirnov test. As it can be seen, the obtained sig value for all variables is higher than .05. Therefore, it can safely be concluded that all these variables are normally distributed across the participants.

\section{Table 1}

The Results of K-S Test for Task, Emotion, and Avoidance

\begin{tabular}{lccc}
\hline & \multicolumn{3}{c}{ Kolmogorov-Smirnov } \\
\cline { 2 - 4 } & Statistic & $\mathrm{df}$ & Sig. \\
\hline Task & .072 & 104 & $.192^{*}$ \\
Emotion & .067 & 104 & $.200^{*}$ \\
Avoidance & .066 & 104 & $.200^{*}$ \\
Self-regulation & .071 & 104 & $.200^{*}$ \\
Motivation & .073 & 104 & $.200^{*}$ \\
Metacognition & .078 & 104 & $.190^{*}$ \\
WTC & .054 & 104 & $.200^{*}$ \\
\hline
\end{tabular}

Table 2 presents descriptive statistics of EFL learners' coping strategies (task, emotion, and avoidance), self-regulation and WTC. As it can be seen, among the three coping strategies, task obtains the highest mean (53.8615), and avoidance (43.7308) receives the lowest mean.

Table 2

Descriptive Statistics of Coping Strategies (Task, Emotion, and Avoidance), Self-Regulation and WTC

\begin{tabular}{lccccc}
\hline & $\mathrm{N}$ & Minimum & Maximum & Mean & SD \\
\hline Task & 130 & 24.00 & 79.00 & 53.86 & 10.90 \\
Emotion & 130 & 23.00 & 71.00 & 46.12 & 10.01 \\
Avoidance & 130 & 22.00 & 65.00 & 43.73 & 9.07 \\
Self-regulation & 130 & 47.00 & 124.00 & 92.87 & 15.21 \\
WTC & 130 & 41.00 & 127.00 & 81.50 & 17.15 \\
Valid N (listwise) & 130 & & & & \\
\hline
\end{tabular}

To investigate the relationship between coping strategies, WTC, and self-regulation, multiple Pearson Product-Moment correlations were applied to the data. Table 3 indicates the results.

Table 3

The Correlation Coefficients between Coping Strategies, Self-Regulation, and WTC

\begin{tabular}{llllll}
\hline & 1 & 2 & 3 & 4 & 5 \\
\hline 1. Task & 1.00 & & & & \\
2. Emotion & -.193 & 1.00 & & & \\
3. Avoidance & .112 & $.239^{* *}$ & 1.00 & & \\
4. Self-regulation & $.703^{* *}$ & .049 & $.183^{*}$ & 1.00 & \\
5. WTC & $.323^{* *}$ & .003 & $.198^{* *}$ & $.401^{* *}$ & 1.00 \\
\hline Note. **Correlation is significant at the level of 0.05 & & &
\end{tabular}

According to Table 3, there is a high correlation between task and self-regulation $(r=0.706, p<0.05)$, a 
Concordance between stress coping strategies, willingness to communicate, and metacognitive self-regulation moderate correlation between WTC and task $(r=0.323, p<0.05)$, a moderate correlation between WTC and self-regulation $(r=0.401, p<0.05)$, and a weak correlation between WTC and avoidance $(r=0.198, p<0.05)$.

To delve into the association between task coping strategies and self-regulation, the subscales of self-regulation [motivation (effort, self-efficacy), metacognition (planning and self-monitoring)] were considered in the correlation analysis. Table 4 presents the results.

\section{Table 4}

The Correlation Coefficients between Task Coping Strategy and the Components of Self-Regulation

\begin{tabular}{|c|c|c|c|c|c|c|c|}
\hline & 1 & 2 & 3 & 4 & 5 & 6 & 7 \\
\hline 1. Task & 1.00 & & & & & & \\
\hline 2. Planning & $.714^{* *}$ & 1.00 & & & & & \\
\hline 3. Self-monitoring & $.642^{* *}$ & $.792^{* *}$ & 1.00 & & & & \\
\hline 4.Effort & $.617^{* *}$ & $.724^{* * *}$ & $.730^{* *}$ & 1.00 & & & \\
\hline 5. Self-efficacy & $.488^{* *}$ & $.660^{* *}$ & $.577^{* *}$ & $.618^{* *}$ & 1.00 & & \\
\hline 6. Metacognition & $.719^{* *}$ & $.953^{* *}$ & $.940^{* *}$ & $.788^{* *}$ & $.656^{* *}$ & 1.00 & \\
\hline 7. Motivation & $.610^{* *}$ & $.768^{* *}$ & $.722^{* *}$ & $.887^{* *}$ & $.887^{* *}$ & $.911^{* * *}$ & 1.00 \\
\hline
\end{tabular}

Note. ${ }^{* *}$ Correlation is significant at the level of 0.05

As the table reveals, both components of self-regulation, i.e., metacognition $(r=0.719, p<0.05)$, and motivation $(r=0.610, p<0.05)$ have high correlation with task coping strategy. The highest correlation are observed between task and metacognition $(r=0.401, p<0.05)$, followed by task and planning $(r=0.714, p<$ $0.05)$, task and effort $(r=0.617, p<0.05)$.

Identical analysis was conducted for task coping strategy and the subscales of WTC (speaking, reading, writing, and listening)

\section{Table 5}

The Correlation Coefficients between Task Coping Strategy and the Components of WTC

\begin{tabular}{llllll}
\hline & 1 & 2 & 3 & 4 & 5 \\
\hline 1. Task & 1.00 & & & & \\
2. WTC in speaking & $.324^{* *}$ & 1.00 & & & \\
3. WTC in reading & $.212^{* *}$ & $.612^{* *}$ & 1.00 & \\
4. WTC in writing & $.245^{* *}$ & $.481^{* *}$ & $.554^{* *}$ & 1.00 & \\
5. WTC in listening & $.278^{* *}$ & $.435^{* *}$ & $.578^{* *}$ & $.656^{* *}$ & 1.00 \\
\hline Note. ${ }^{* *}$ Correlation is significant at the level of 0.05 & & &
\end{tabular}

According to table 5, regarding the relationship between task and the four components of WTC, the highest correlation is observed between WTC in speaking and task $(r=0.714, p<0.05)$. The other components demonstrate quite identical correlations: reading $(r=0.212, p<0.05)$, writing $(r=0.245, p<0.05)$, and listening $(r=0.278, p<0.05)$.

To delve into the relationship between WTC and self-regulation, the subscales of self-regulation were entered into correlation analysis Table 6 represents the results.

\section{Table 6}

The Correlation Coefficients between WTC and the Components of Self-regulation

\begin{tabular}{|c|c|c|c|c|c|c|}
\hline & Planning & Monitoring & Effort & Efficacy & Metacognition & Motivation \\
\hline WTC & $.382^{* *}$ & $.241^{* *}$ & $.313^{* *}$ & $.433^{* *}$ & $.334^{* *}$ & $.418^{* *}$ \\
\hline
\end{tabular}

As the table reveals, WTC has the highest correlation with the motivation component of self-regulation $(r=$ $0.4718, p<0.05)$. 


\section{Discussion}

As stated before, the present study sought to delve into willingness to communicate in relation with selfregulation and coping strategy. The results of the present study demonstrated that among three sub-components of coping strategies, only emotion had no significant relationship with WTC. The other two components (Task and Avoidance) had a positive and significant relationship with WTC. So, the null hypothesis is rejected. The highest correlation was observed between WTC and task. The task-oriented strategy is problem-focused. It involves taking direct action to alter the situation itself to reduce the amount of stress it evokes. In the emotion-oriented strategy, efforts are directed at altering emotional responses to stressors. It also includes attempts to reframe the problem in such a way that it no longer evokes a negative emotional response and elicits less stress (Mattlin, 1990). Finally, avoidance-oriented coping includes strategies such as avoiding the situation, denying its existence, or losing hope (Lazarus \& Folkman, 1984). It also includes the use of indirect efforts to adjust to stressors by distancing oneself, evading the problem, or engaging in unrelated activities for the purpose of reducing feelings of stress (Roth \& Cohen, 1986). Furthermore, the results revealed that learners who are using task-oriented strategy are more willing to communicate. So, it seems plausible that in a stressful context in which students are more eager to involve in taking direct action to alter the situation itself to reduce the amount of stress, they are also more eager to communicate. So, this strategy enhances learners' communicative engagement in stressful context.

The results of correlation coefficients between self-regulation and WTC indicated that self- regulation had a positive and significant relationship with WTC. So, the null hypothesis was rejected. According to Zimmerman (1990), self-regulated learning (SRL) describes learners who are more mastery-oriented and tend to understand better their own learning process. Such learners assume initiative and responsibility for their own learning and appear to be self-motivated, strategic, and effective; they also tend to attribute failure to lack of effort or strategies; therefore, they are more motivated to improve through expending more effort and attempting different learning strategies in the face of failure. In contrast, less self-regulated learners would typically show a lack of interest and strategies in learning. They avoid seeking help and become defensive regarding their lack of learning strategies because they tend to attribute failure to their personal limitations in intelligence and abilities. Thus, they often rely on instructions or accommodations of others to help them communicate more effectively.

The finding of the present study is consistent with studies conducted by Heidari Soureshjani (2013), Nosratinia and Deris (2015), Rajabpour, Ghanizadeh, and Ghonsooly (2015), Ghanizadeh, Eishabadi, and Rostami (2015). Heidari Soureshjani (2013) explored the interrelationship of English as a Foreign Language (EFL) learners' self-regulation, willingness to communicate (WTC), and their oral presentation performance through correlational analysis. The results revealed that there is a significant relationship between the self-regulation degree of language learners and their oral performance. Besides, there is a strong, positive relationship between the WTC degree of learners and their oral presentation performance. In addition, Nosratinia and Deris (2015) investigated the association between Willingness to Communicate (WTC) and Self-Regulation (SR) among Iranian English as a Foreign Language (EFL) learners using Spearman's rank-order correlation. The analysis outcomes suggested a significant direct correlation between SR and WTC. Moreover, Ghanizadeh, Eishabadi, and Rostami (2015) found that WTC correlated significantly and positively with criterion measure. Criterion measure assesses the learners' intended efforts toward learning English; in other words, it seeks to find to what extent learners like to spend time studying English. So, it seems conceivable that learners who want to exert ample effort in learning English are more willing to communicate and use the second language in the classroom.

The results of correlation coefficients between self-regulation and coping strategies indicated that all subcomponents of self- regulation had a positive and significant relationship with the task coping strategy. So, the null hypothesis was rejected. The finding of the present study is consistent with the Winterbach's study (2007). Winterbach conducted a study to explore qualitative differences in the self-regulation of stress management between students experiencing high stress levels and those experiencing low stress levels. The 
Concordance between stress coping strategies, willingness to communicate, and metacognitive self-regulation

results indicated that participants with lower stress were better self-regulators. They were slightly more mindful regarding perceived causes of stress, had more intrinsically motivated goals, had higher self-efficacy beliefs, more often used physical activity and external monitoring in executing their stress goals, judged themselves more positively, and reflected more positively on the self-regulation process. Therefore, it can be concluded that, learners who are more mastery-oriented and tend to understand better their own learning process, in other words, more self-regulated learners, are more skillful in managing and controlling stress by taking direct action to alter the situation itself to reduce the amount of stress it.

\section{Conclusion}

Taken together, the research findings yielded various recommendations for curriculum development, educators, and English students by unfolding the variables affecting L2 WTC. As task and avoidance coping strategies positively correlated with WTC in English, it can be concluded that providing a relaxing classroom environment where students help each other and feel less anxious and stress to communicate in English inside the classroom and the tasks are challenging and interesting would help language learners to be more willing to communicate in their English classrooms. Therefore, the more knowledge language teachers have about learning environment and students, the better capable they will be to minimize their stress and maximize their state of readiness to communicate (Cameron, 2013). Moreover, considering the importance of the communicative approach to second language teaching and its emphasis on communicative effectiveness (Allwright \& Bailey, 1996, as cited in Cameron, 2013), teachers should be aware of the communication orientation activities to support students in their endeavors to achieve communicative competence. In addition, as self-regulation plays a noticeable role in the willingness to communicate of language learners, teachers should reflect upon their teaching strategies and activities to assist learners manage, control, and elevate their self-regulation abilities. L2 curriculum developers are recommended to design appropriate materials and activities by which involve L2 teachers and learners engage in a cooperative process, where it would be easier to promote WTC and SR. Lastly, the study may suffer from a set of limitations. In this study, variables were surveyed through questionnaires. Future researchers are recommended to utilize qualitative longitudinal studies. These studies should use case studies, observations, and interviews to provide profound insight into the concept.

\section{References}

Allwright, D., \& Bailey, K. (1996). Focus on the language classroom: An introduction to classroom research for language teachers. Cambridge: Cambridge University Press.

Boekaerts, M. (1997). Self-regulated learning: A new concept embraced by researchers, policy makers, educators, teachers, and students. Learning and Instruction, 7(2), 11-186. http://dx.doi.org/10.1016/S0959-4752(96)00015-1

Cameron, D. (2013). Willingness to communicate in English as a second language as a stable trait or context-influenced variable: Case studies of Iranian migrants to New Zealand. Australian Review of Applied Linguistics, 36(2), 177-195.

Dörnyei, Z. (2005). The psychology of language learner: Individual differences in second language acquisition. Mahwah, NJ: Lawrence Erlbaum.

Endler, N. S., \& Parker, J. D. A. (1990). Coping Inventory for Stressful Situations (CISS): Manual. Toronto, Ontario, Canada: Multi-Health Systems.

Endler, N. S., \& Parker, J. D. A. (1999). Coping Inventory for Stressful Situations (CISS): Manual (2nd ed.). Toronto, Ontario, Canada: Multi-Health Systems.

Ghanizadeh, A., Eishabadi, N., \& Rostami, S. (2015). Motivational dimension of willingness to communicate in L2: The impacts of criterion measure, ideal L2 self, family influence, and attitudes to L2 culture. International Journal of Research Studies in Education, 5(3), 1-12.

Ghanizadeh, A., \& Rostami, S. (2015). A Dörnyei-inspired study on second language motivation: A cross-comparison analysis in public and private contexts. Psychological Studies, 60(3), 292-301. 
Atrian, A., Ghanizadeh, A., \& Rostami, S. http://dx.doi.org/10.1007/s12646-015-0328-4

Ghanizadeh, A., \& Royaei, N. (2015). Emotional facet of language teaching: emotion regulation and emotional labor strategies as predictors of teacher burnout. International Journal of Pedagogies and Learning, 10(2), 139-150. http://dx.doi.org/10.1080/22040552.2015.1113847

Greenglass, E. R. (2002). Proactive coping and quality of life management. In E. Frydenberg (Ed.), Beyond coping: Meeting goals, visions, and challenges (pp. 37-62). London: Oxford University Press. http://dx.doi.org/10.1093/med:psych/9780198508144.003.0003

Heidari Soureshjani, K. (2013). A study on the effect of self-regulation and the degree of willingness to communicate on oral presentation performance of EFL learners. International Journal of Language Learning and Applied Linguistics World, 4(4), 166-177.

Lazarus, R. S. (1991). Emotion and adaptation. New York: Oxford University Press.

Lazarus, R. S., \& Folkman, S. (1984). Stress, appraisal and coping. New York: Springer.

MacIntyre, P. D., Baker, S. C., Clément, R., \& Conrad, S. (2001). Willingness to communicate, social support, and language-learning orientations of immersion students. Studies in Second Language Acquisition, 23, 369-388. http://dx.doi.org/10.1017/S0272263101003035

MacIntyre, P. D., Baker, S. C., Clément, R., \& Donovan, L. A. (2003). Talking in order to learn: Willingness to communicate and intensive language programs. The Canadian Modern Language Review, 59, 587-605. http://dx.doi.org/10.3138/cmlr.59.4.589

MacIntyre, P. D., Clément, R., Dörnyei, Z., \& Noels, K. A. (1998). Conceptualizing willingness to communicate in a L2: A situational model of L2 confidence and affiliation. The Modern Language Journal, 82, 545-562. http://dx.doi.org/10.1111/j.1540-4781.1998.tb05543.x

Mattlin, J. A. (1990). Situational determinants of coping and coping effectiveness. Journal of Health and Social Behavior, 31(1), 103-122. http://dx.doi.org/10.2307/2137048

McCroskey, J. C., \& Baer, J. E. (1985, November).Willingness to communicate: The construct and its measurement. Paper presented at the annual meeting of the Speech Communication Association, Denver, CO. ERIC Document Reproduction Service No. E.d. 265-604.

McCroskey, J. C., \& Richmond, V. P. (1991). Quiet children and the classroom teacher. Bloomington, IN: ERIC Clearinghouse on Reading and Communication Skills.

Murray, D. W., Rosanbalm, K., Christopoulos, C., \& Hamoudi, A. (2015). Self-regulation and toxic stress: Foundations for understanding self-regulation from an applied developmental perspective. OPRE Report \#2015-21. Washington, DC: Office of Planning, Research and Evaluation, Administration for Children and Families, U.S. Department of Health and Human Services.

Muraven, M., \& Baumeister, R. F. (2000). Self-regulation and depletion of limited resources: Does self-control resemble a muscle? Psychological Bulletin, 126, 247-259. http://dx.doi.org/10.1037/0033-2909.126.2.247

Nosratinia, M., \& Deris, Z. (2015). An exploration into the relationship between EFL learners' self-regulation and willingness to communicate. Theory and Practice in Language Studies, 5(9), 1921-1928. http://dx.doi.org/10.17507/tpls.0509.22

Pintrich, P. R. (2004). A conceptual framework for assessing motivation and self-regulated learning in college students. Educational Psychology Review, 16, 385-407. http://dx.doi.org/10.1007/s10648-004-0006-x

Pritchard, M. E., \& McIntosh, D. N. (2003). What predicts psychological outcomes among law students: a longitudinal panel study? Journal of Social Psychology, 143, 727-745. http://dx.doi.org/10.1080/00224540309600427

Rajabpour, M., Ghanizadeh, A., \& Ghonsooly, B. (2015). A study of motivational facet of language use in the light of Dornyei's L2 Motivational Self-system. Journal of Applied Linguistics and Language Research, 2(5), 179-196.

Roth, S., \& Cohen, L. J. (1986) Approach, avoidance, and coping with stress. American Psychologist, 41,813-819. http://dx.doi.org/10.1037/0003-066X.41.7.813

Schunk, D. H. (2001). Social cognitive theory and self-regulated learning. In B. J. Zimmerman \& D. H. Schunk (Eds.), Self-regulated learning and academic achievement: Theoretical perspectives (2nd ed., pp. 
Concordance between stress coping strategies, willingness to communicate, and metacognitive self-regulation

125-151). Mahwah, NJ: Erlbaum.

Schunk, D. H., \& Zimmerman, B. J. (1997). Social origins of self-regulatory competence. Educational Psychologist, 32, 195-208. http://dx.doi.org/10.1207/s15326985ep3204_1

Schunk, D. H., \& Zimmerman, B. J. (1998). Self-regulated learning: From teaching to self-reflective practice. New York: Guilford.

Trevisani, C. (2014). A correlational study of self-regulated learning, stress and mindfulness (Unpublished doctoral dissertation). King's University College at Western University London, Canada.

Vanderstoep, S. W., Pintrich, P. R., \& Fagerlin, A. (1996). Disciplinary differences in self-regulated learning in college students. Contemporary Educational Psychology, 21, 345-362. http://dx.doi.org/10.1006/ceps.1996.0026

Varasteh, H., Ghanizadeh, A., \& Akbari, O. (2016). The role of task value, self-regulation, and ambiguity tolerance in predicting EFL learners' test anxiety, learning strategies, and language achievement. Psychological Studies, 61(1), 2-12. http://dx.doi.org/10.1007/s12646-015-0351-5

Wilson. D. K., Wallston, K. A., \& King, J. E. (1990). Effects of contract framing, motivation to quit, and self-efficacy on smoking reduction. Journal of Applied Social Psychology, 20, 531-547. http://dx.doi.org/10.1111/j.1559-1816.1990.tb00426.x

Winterbach, L. (2007). Self-regulation and stress management in undergraduate students (Unpublished masteral thesis). North-West University, Potchefstroom.

Wolters, C. A., \& Pintrich, P. R. (1998). Contextual differences in student motivation and self-regulated learning in mathematics, English, and social studies classroom. Instructional Science, 26, 27-47. http://dx.doi.org/10.1023/A:1003035929216

Xu, X., Liu, B., Zou, P., Zhang,Y., You, J., \& Pei, F. (2014). Silencing of LASS2/TMSG1 enhances invasion and metastasis capacity of prostate cancer cell. Journal of Cellular Biochemistry, 115(4), 731-743. http://dx.doi.org/10.1002/jcb.24716

Zafarmand, A., Ghanizadeh, A., \& Akbari, O. (2014). a structural equation modeling of EFL learners' goal-orientation, metacognitive awareness, and self-efficacy. Advances in Language and Literary Studies, 5(6), 112-124.

Zeidner, M., Boekaerts, M., \& Pintrich, P. R. (2000). Self-regulation: Directions and challenges for future research. In M. Boekaerts, P. R. Pintrich, \& M. Zeidner (Eds.), Handbook of self-regulation (pp. 749-768). San Diego: Academic Press. http://dx.doi.org/10.1016/B978-012109890-2/50052-4

Zimmerman, B. J. (1990). Self-regulated learning and academic achievement: An overview. Educational Psychologist, 25, 3-17. http://dx.doi.org/10.1207/s15326985ep2501_2

Zimmerman, B. J. (2002). Becoming a self-regulated learner: An overview. Theory into Practice, 41, 64-72. http://dx.doi.org/10.1207/s15430421tip4102__2

Zimmerman, B. J., \& Bandura, A. (1994). Impact of self-regulatory influences on writing course attainment. American Educational Research Journal, 31, 845-862. http://dx.doi.org/10.3102/00028312031004845

Zimmerman, B. J., \& Martinez-Pons, M. (1986). Development of a structured interview for assessing student use of self-learning strategies. American Educational Research Journal, 23, 614-628. http://dx.doi.org/10.3102/00028312023004614

Zimmerman, B. J., \& Martinez-Pons, M. (1988). Construct validation of a strategy model of student self-regulated learning. Journal of Educational Psychology, 80, 284-290. http://dx.doi.org/10.1037/0022-0663.80.3.284

Zimmerman, B. J., \& Schunk, D. H. (Eds.). (2001). Self-regulated learning and academic achievement: theoretical perspectives (2nd ed.). Mahwah, NJ: Erlbaum. 
Atrian, A., Ghanizadeh, A., \& Rostami, S. 